\title{
Involvement of NO in Antinociception of NSAIDS in Murine Formalin Hind Paw Assay
}

\author{
Authors \\ Viviana Noriega ${ }^{1}$, Hugo F. Miranda르, Juan Carlos Prieto ${ }^{3}$, Ramón Sotomayor-Zárate ${ }^{4}$, Fernando Sierralta ${ }^{3}$
}

\author{
Affiliations \\ 1 Universidad de Chile, Facultad de Medicina, Hospital \\ Clinico, Cardiovascular Department, Santiago, Chile \\ 2 Universidad de Chile, Facultad de Medicina, Neuro- \\ science, Santiago, Chile \\ 3 Universidad de Chile, Facultad de Medicina, Pharma- \\ cology, Santiago, Chile \\ 4 Universidad de Valparaíso, Instituto de Fisiología, \\ Valparaíso, Chile
}

Key words

anti-inflammatory drugs, pharmacology, inflammation

received $\quad 13.12 .2019$

accepted $\quad 13.01 .2020$

\section{Bibliography}

DOI https://doi.org/10.1055/a-1095-5418

Published online: 30.1 .2020

Drug Res 2020; 70: 145-150

(c) Georg Thieme Verlag KG Stuttgart · New York

ISSN 2194-9379

\author{
Correspondence \\ Dr. Hugo F. Miranda \\ Universidad de Chile, Facultad de Medicina, Neuroscience, \\ Independencia 1027 \\ 775000 Santiago \\ Chile
}

Tel.: 229786237, Fax : 9786237

hmiranda@med.uchile.cl

\begin{abstract}
There are different animal models to evaluate pain among them the formalin hind paw assay which is widely used since some of its events appear to be similar to the clinical pain of humans. The assay in which a dilute solution of formalin is injected into the dorsal hindpaw of a murine produces two 'phases' of pain behavior separated by a inactive period. The early phase (Phase I) is probably due to direct activation of nociceptors and the second phase (Phase II) is due to ongoing inflammatory input and central sensitization. Mice were used to determine the potency antinociceptive of piroxicam $(1,3,10$, and $30 \mathrm{mg} / \mathrm{kg})$, parecoxib $(0.3,1,3,10$ and $30 \mathrm{mg} / \mathrm{kg})$, dexketoprofen $(3,10,30$ and $100 \mathrm{mg} / \mathrm{kg})$ and ketoprofen $(3,10,30$ and $100 \mathrm{mg} / \mathrm{kg})$. Dose-response for each NSAIDs were created before and after $5 \mathrm{mg} / \mathrm{kg}$ of L-NAME i.p. or $5 \mathrm{mg} / \mathrm{kg}$ i.p. of 7-nitroindazole. A least-squares linear regression analysis of the log dose-response curves allowed the calculation of the dose that produced $50 \%$ of antinociception (ED50) for each drug. The ED50 demonstrated the following rank order of potency, in the phase I: piroxicam > dexketoprofen > ketoprofen $>$ parecoxib and in the phase II: piroxicam $>$ ketoprofen $>$ parecoxib $>$ dexketoprofen. Pretreatment of the mice with LNAME or 7-nitroindazol induced a significant increase of the analgesic power of the NSAIDs, with a significant reduction of the ED50. It is suggested that NO may be involved in both phases of the trial, which means that nitric oxide regulates the bioactivity of NSAIDs.
\end{abstract}

\section{Introduction}

Pain is a considerable unpleasant sensory experience that may be severe to moderate, with transitory or plain intensity and transitory or persistent duration, characteristics that are associated with different types of pain, whether nociceptive, inflammatory or neuropathic. There are different animal models to evaluate pain among them, the formalin test should be mentioned [1]. The formalin test has been widely used in pain investigations, since it was reported by Dubuisson and Dennis [2]. The assay in which a dilute solution of formalin is injected into the dorsal or plantar hindpaw of a murine produces two 'phases' of pain behavior separated by a inactive period. The early phase (Phase I) is probably due to direct activation of nociceptors through TRPA1 (transient receptor potential an- kyrin subtype 1 protein) channels and the second phase (Phase II) is due to ongoing inflammatory input and central sensitization [3].

The formalin test, for antinociception, has been evaluated as an essay that , associates moderate, continuous pain generated by injured tissue and differs from most traditional tests of nociception which rely upon brief stimuli of threshold intensity [3]. This test is widely used because some of its events appear to be similar to the clinical pain of humans. The analysis of the mechanism of action of the formalin test has been the subject of numerous studies demonstrating the role of most pronociceptive modulators, such as norepinephrine, serotonin, substance $P$, neuroquinines, cytokines, acetylcholine, glutamate, capsaicin, nitric oxide and many others [4]. 
Among the pronociceptive mediators of the formalin hind paw assay is the nitric oxide (NO). NO is a molecular gas generated by the activity of nitric oxide synthase (NOS). Three different forms of NOS have been identified: neuronal NOS (nNOS, type 1 NOS); inducible NOS, (iNOS, type 2 NOS); endothelial NOS (eNOS, type 3 NOS) and in some tissues they may exist in the mitochondria (mNOS). nNOS contributes to the NO nociception by upregulation of the spinal cord after noxious stimulation. Besides, pharmacologic inhibition of nNOS attenuates nerve injury-induced mechanical hypersensitivity in mice. iNOS repair of injured tissue and is involved in the development of hypersensitivity to pain in inflammatory and neuropathic pain models. NO generated by eNOS may modulate acute tissue inflammation. It has been reported that NO produced in excess by iNOS and nNOS has been implicated in processes such as pain and inflammation $[5,6]$. It should be remembered that several studies have shown that NO is able to induce pro- or anti-nociception depending on the locally concentrations of NO produced locally, the via of administration or application $[7,8]$.

On the other hand, the NO produced by the three isoforms of NOS, is subject to inhibition that is beneficial in shock, inflammation and neurolesion. Pharmacological inhibition of NOS can be carried out by different agents, including arginase, calmodulin, amino guanidine, $\mathrm{N}^{\mathrm{G}}$-nitro-L-arginine methyl ester (L-NAME), 7-nitro-indazole and others. The antinociception induced by these agents it has been informed. Moore et al., 1991 and 1993 [9, 10] reports that the last two nitric oxide biosynthesis inhibitors, produces antinociceptive activity. This findings provides support that $\mathrm{NO}$ is a mediator of pain. It was reported that L-NAME, induced a dose-dependent stereospecific inhibition of the second phase of formalin paw test, with minimal effect on the first phase [11]. In addition, pretreatment with L-NAME significantly reduced licking behavior induced by formalin into the left hindpaw. The results suggest that NO is associated with nociception. Besides, L-NAME produced a dose-dependent antinociceptive activity in the acetic acid writhing test, intraplantar paw carrageenan [12]. It has also been reported that NOS inhibitors: L-NAME, 7-nitro-indazole and amino guanidine reduced nociception of phase II of the formalin hind paw, without modify phase I, with the exception of L-NAME that decreased it [13].

It is recognized that the nociceptive activity of formalin is directly dependent on the relative concentration injected in the hind paw.. Low concentrations of formalin ( 0.125 and $0.5 \%$ ) produce only the neurogenic phase or phase I, acute or phasic. Administration from $2 \%$ of formalin induced also the inflammatory phase or phase II, tonic. Pretreatment with L-NAME resulted in a significant inhibition of the paw-licking response induced by both concentrations of formalin [14]. On the other hand, the administration of 7-nitro-indazole induced antinociceptive activity, in the same animal pain model.

According to the previous backgrounds, L-NAME and 7-nitroindazole, have properties that allow it to act either as a pronociceptive agent or as an antinociceptive agent, against different agents. Established this dichotomy, in this work was evaluated whether the effect of L-NAME and 7-nitroindazole are involved in the antinociceptive activity of NSAIDs using the formalin test in mice paw.

\section{Materials and Methods}

\section{Animals}

Male CF-1 mice (28-30 g), housed on a $12 \mathrm{~h}$ light-dark cycle at $22 \pm 2{ }^{\circ} \mathrm{C}$ with access to food and water ad libitum, were used. Experiments were performed in accordance with current Guidelines for The Care of Laboratory Animals and Ethical Guidelines for investigation of experimental pain approved by the Animal Care and Use Committee of the Faculty of Medicine, University of Chile. Animals were acclimatized to the laboratory for at least $1 \mathrm{~h}$ before testing, used only once in the protocol and were euthanized by intraperitoneal (i.p.) injection of $65 \mathrm{mg} / \mathrm{kg}$ of pentobarbital. In each protocol was used a minimum mice (6-8) to reach definitive results of the drug treatments.

\section{Nociceptive test}

Antinociception was assessed by the formalin hind paw assay as previously described [15], using $20 \mu \mathrm{L}$ of $2 \%$ formalin solution injected into the dorsal surface of the right hind paw of the mice with a 27 -gauge needle attached to a $50-\mu \mathrm{L}$ Hamilton syringe. The degree of pain intensity was assessed as the total time, in seconds, spent by the animal licking or biting the injected paw. The test shows two clear-cut periods: phase I corresponding to the 5-min period starting immediately after the formalin injection and described as phasic and neurogenic, resulting from direct activation of chemical nociceptors, whereas phase II, inflammatory, recorded as the 10 -min. period starting $20^{\circ}$ min after the formalin injection and responses result from the central sensitization of nociceptive pathways leading to motor responses. Control saline animals licking were $126.38 \pm 8.48$ and $155.65 \pm 10.20$ phase I and phase II, respectively and $n=24$ for each phase). The licking times observed were converted to \% of maximum possible effect ( $\% \mathrm{MPE}$ ) as follows:

$\% \mathrm{MPE}=100-[(100 \times$ post-drug licking time $) /$ control licking time $]$

\section{Protocol}

In order to determine the relative potency antinociceptive de each NSAIDs, dose-response curves, were obtained for piroxicam $(1,3,10$, and $30 \mathrm{mg} / \mathrm{kg})$, parecoxib $(0.3,1,3,10$ and $30 \mathrm{mg} / \mathrm{kg})$, dexketoprofen $(3,10,30$ and $100 \mathrm{mg} / \mathrm{kg})$ and ketoprofen $(3,10,30$ and $100 \mathrm{mg} / \mathrm{kg}$ ) were obtained using at least six to eight animals at each of at least four doses administered i.p. Dose-response for each NSAIDs were created before and after $5 \mathrm{mg} / \mathrm{kg}$ of L-NAME i.p. or $5 \mathrm{mg} / \mathrm{kg}$ i.p. of 7-nitroindazole. A least-squares linear regression analysis of the log dose-response curves allowed the calculation of the dose that produced $50 \%$ of antinociception $\left(E D_{50}\right)$ for each drug.

\section{Drugs}

The drugs were freshly dissolved in a physiological salt solution of $10 \mathrm{mg} / \mathrm{kg}$ for i.p. administration. Piroxicam was provided by Pfizer Chile, parecoxib by Pfizer Chile, ketoprofen by Rhone- Poulenc Rorer, dexketoprofen was a gift from Menarini Laboratories, Spain. $\mathrm{N}^{\mathrm{w}}$-nitro-L-arginine methyl ester hydrochloride (L-NAME) and 7-nitroindazol,were purchased from Sigma-Aldrich Chemical Co, St.- Louis, MO, USA. 


\section{Statistical analysis}

Results are presented as means \pm SEM. Statistical difference between before and after the treatment with L-NAME or 7-nitroindazol was assessed by Student's test for independent means and $p$ values less than $0.05(p<0.05)$ were considered statistically significant. Statistical analyses were performed using the program (Pharm Tools Pro, version 1.27, McCary Group Inc., PA).

\section{Results}

\section{NSAIDs antinociception in hind paw formalin test}

The i.p. administration of the different doses of piroxicam, parecoxib, dexketoprofen or ketoprofen induced a dose-related antinociception accompanied by different potency in both phases of the hind paw formalin test, as can be seen in > Figs. 1 and 2. The $\mathrm{ED}_{50}$ values in $\mathrm{mg} / \mathrm{kg}$, demonstrated the following rank order of potency of the mice licking or biting the injected paw, in the phase I: piroxicam > dexketoprofen > ketoprofen > parecoxib and in the phase II: piroxicam $>$ ketoprofen $>$ parecoxib $>$ dexketoprofen, see $>$ Table 1.

\section{Effect of L-NAME on the NSAIDs antinociception in hind paw formalin test}

The pretreatment of mice with $5 \mathrm{mg} / \mathrm{kg}$ i.p. of L-NAME, dose with does not induce any significant change in the basal antinociception or behavior of the mice, nevertheless, produced a significant increase of the $\mathrm{ED}_{50}$ of both phases of piroxicam, parecoxib, dexketoprofen and ketoprofen, as shown in > Figs. $\mathbf{3}$ and $\mathbf{4}$.
The order of increase of the ED50 induced by L-NAME in phase I of the NSAIDs in the formalin test was: ketoprofen (5.88) > dexketoprofen (4.96) > piroxicam (2.28) > parecoxib (1.55). Moreover, in phase II the order was: ketoprofen (6.95) > piroxicam (5.15) > parecoxib (4.03) > dexketoprofen (3.85).

\section{Effect of 7-nitroindazole on the NSAIDs antinociception in hind paw formalin test}

The pretreatment of mice with $5 \mathrm{mg} / \mathrm{kg}$ i.p. of 7-nitroindazole, a dose with does not induce any significant change in the basal antinociception or behavior of the mice, nevertheless, produced a significant increase of the $\mathrm{ED}_{50}$ of both phases of piroxicam , parecoxib, dexketoprofen and ketoprofen, as shown in $>$ Figs. $\mathbf{3}$ and $\$ \mathbf{4}$.

The order of increase of the ED50 induced by 7-nitroindazole in phase I of the NSAIDs in the formalin test was: piroxicam (9.68), ketoprofen (6.21) > dexketoprofen (5.01) > parecoxib (4.94). Furthermore, in phase II the order was: ketoprofen (6.79) > dexketoprofen (6.14) > parecoxib (5.38) > piroxicam (2.98).

\section{Discussion}

The present study was performed to determine the antinociceptive and anti-inflammatory activities of four NSAIDs using the hind paw formalin test and if the effects induced by L-NAME and 7-nitroindazole are involved in the activity of NSAIDs The results demonstrated that piroxicam, parecoxib, dexketoprofen and ketoprofen are able to inhibit both phases of the hind paw formalin test.

The findings of this work are in agreement with the typical biphasic response reported previously $[2,3,15]$. Phase I results from
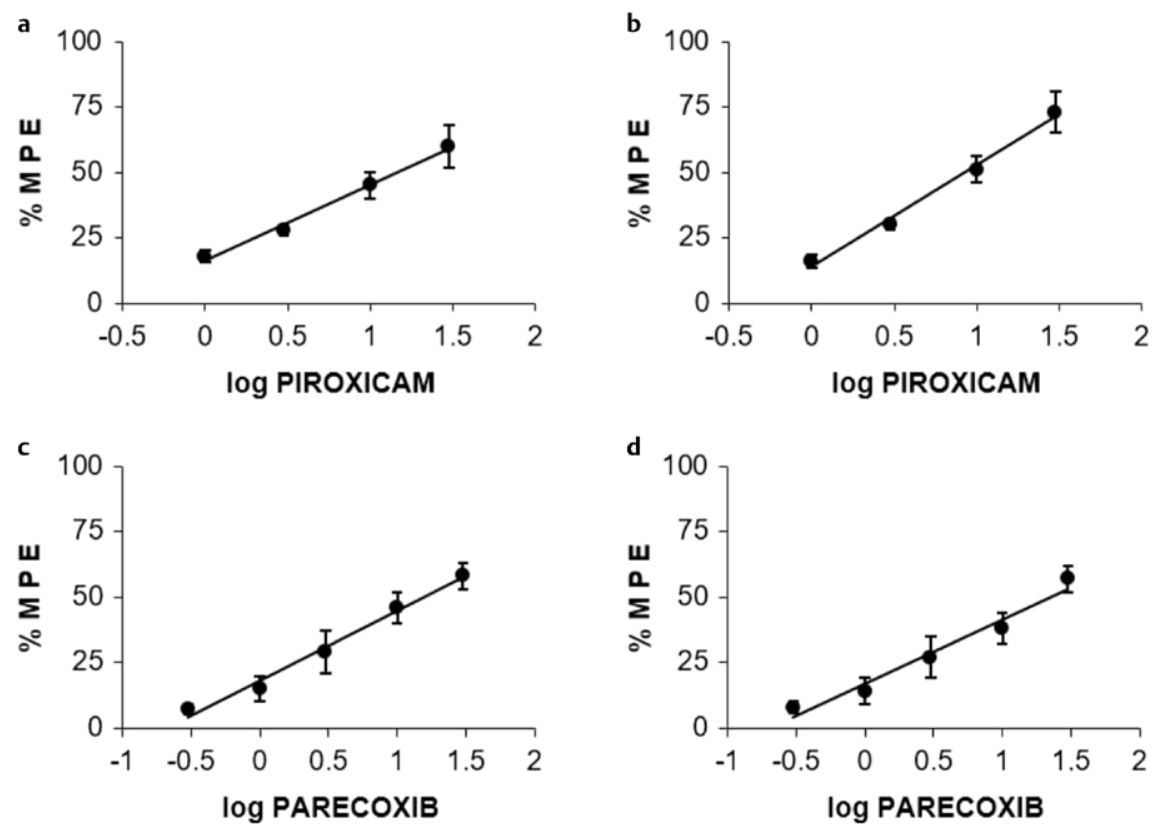

- Fig. 1 Dose-response curves for the antinociceptive activity induced by piroxicam in phase I (1a) and in phase II (1b) and by parecoxib in phase I (1c) and in phase II (1d) in the formalin hind paw assay. Each point is the mean with \pm SEM of $6-8$ mice. \% MPE = antinociception evaluated as percentage of maximum possible effect. 

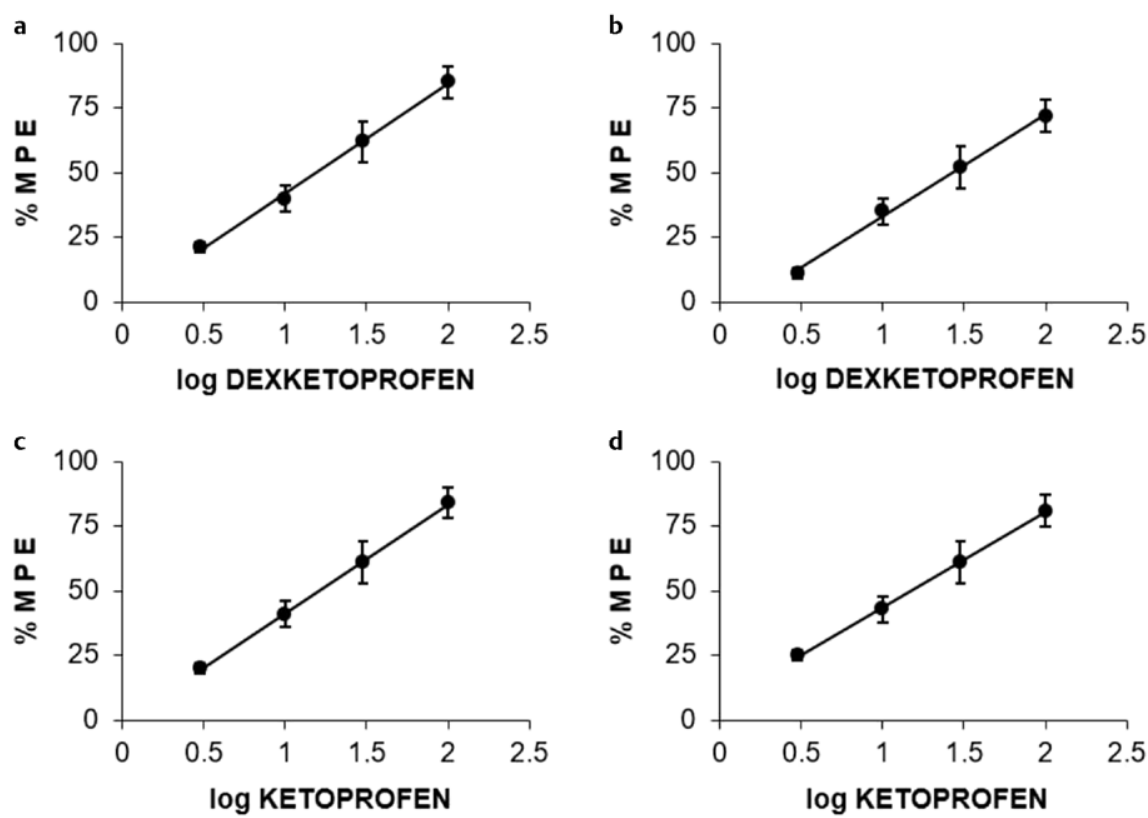

- Fig. 2 Dose-response curves for the antinociceptive activity induced by dexketoprofen in phase I (2a) and in phase II (2b) and by ketoprofen in phase I (2c) and in phase II (2d) in the formalin hind paw assay. Each point is the mean with \pm SEM of 6-8 mice. \% MPE = antinociception evaluated as percentage of maximum possible effect.

- Table $1 \quad \mathrm{ED}_{50}$ values (mean \pm SEM) for the antinociception induced by piroxicam, parecoxib, dexketoprofen and ketoprofen administered i.p. in the formalin hind paw assay of mice after pretreatment of $5 \mathrm{~m} \mathrm{~g} / \mathrm{kg}$, i.p. of L-NAME, and $5 \mathrm{mg} / \mathrm{kg}$ i.p. of 7-nitroindazol.

\begin{tabular}{|l|c|c|}
\hline \multirow{2}{*}{ Drug } & \multicolumn{2}{|c|}{ ED $_{50}$ (mg/kg) } \\
\cline { 2 - 3 } & Phase I & Phase II \\
\hline PIROXICAM CONTROL & $14.53 \pm 0.70$ & $8.51 \pm 0.76$ \\
\hline PIROXICAM + L-NAME & $6.37 \pm 1.15^{*}$ & $1.65 \pm 0.30^{*}$ \\
\hline $\begin{array}{l}\text { PIROXICAM + 7-NITROINDA- } \\
\text { ZOL }\end{array}$ & $1.50 \pm 0.21^{*}$ & $2.85 \pm 0.17^{*}$ \\
\hline PARECOXIB CONTROL & $15.81 \pm 0.57$ & $22.50 \pm 2.10$ \\
\hline PARECOXIB + L-NAME & $10.16 \pm 1.73^{*}$ & $5.57 \pm 0.32^{*}$ \\
\hline PARECOXIB + 7-NITROINDAZOL & $3.20 \pm 0.16^{*}$ & $4.18 \pm 0.25^{*}$ \\
\hline DEXKETOPROFENO CONTROL & $15.35 \pm 0.56$ & $26.53 \pm 3.19$ \\
\hline DEXKETOPROFENO + L-NAME & $3.09 \pm 0.21^{*}$ & $6.89 \pm 0.47^{*}$ \\
\hline $\begin{array}{l}\text { DEXKETOPROFENO + } \\
\text { 7-NITROINDAZOL }\end{array}$ & $3.06 \pm 0.15^{*}$ & $2.04 \pm 0.11^{*}$ \\
\hline kETOPROFENO CONTROL & $15.71 \pm 0.87$ & $14.61 \pm 0.46$ \\
\hline KETOPROFENO + L-NAME & $2.67 \pm 0.10^{*}$ & $2.10 \pm 0.47^{*}$ \\
\hline $\begin{array}{l}\text { KETOPROFENO + 7-NITROIN- } \\
\text { DAZOL }\end{array}$ & $2.53 \pm 0.11^{*}$ & $2.15 \pm 0.15^{*}$ \\
\hline
\end{tabular}

${ }^{*} \mathrm{p}<0.05$ compared to the corresponding control goup. $\mathrm{N}=24$.

direct stimulation of nociceptors, while phase II involves a period of sensitization, during which inflammatory phenomena occur through peripheral mechanisms [1,2]. Though, the results obtained in the present study, differ from previously reported, in that the administration of formalin in this test only produces one phase, being it phase II specifically $[16,17]$.

In the present work, pretreatment of mice with L-NAME resulted in a significant increase in the antinociceptive potency of each NSAID, reflected by a significant decrease in $E D_{50}$, both in phase I and in phase II. This nociceptive increase is consistent with similar effects of L-NAME in diazepam, clonazepam, chlordiazepoxide, tadalafil $[18,19]$. However, this nociceptive increase is not consistent with the decrease in the antinociception induced by L-NAME in modafinil, ketamine, diclofenac, meloxicam and carbamazepine [19-23].

Pretreatment of mice with 7-nitroindazole increased the antinociceptive potency of the NSAIDs used in this study, with the consequent significant decrease in $E D_{50}$, in both phases of the formalin test. This finding is in agreement with a similar effect induced by 7-nitroindazole in diazepam clonazepam,. chlordiazepoxide and tapentadol analgesia $[18,24]$. However, the effect of produced by 7 -nitroindazole is not consistent with the reported for modafinil and dexmedetomidine $[19,25]$. The reasons for these discrepancies could be explained by the different strains of mice, the period of work of the protocol, the different doses used and others.

The significative decrease of the $\mathrm{ED}_{50}$ of the different NSAIDs produced by L-NAME is related to its COXs inhibitory capacity. Phase I is headed by ketoprofen, a so-called non-selective NSAID, followed by dexketoprofen and piroxicam, recognized as COX-1 inhibitors and finally, a COX-2 inhibitor, parecoxib. 7-nitroindazole, in this phase, decrease the $\mathrm{ED}_{50}$ of piroxicam, first, then to ketoprofen and dexketoprofen and ends with parecoxib. The increase in NSAID potency, expressed by the decrease in its ED50, in the case 


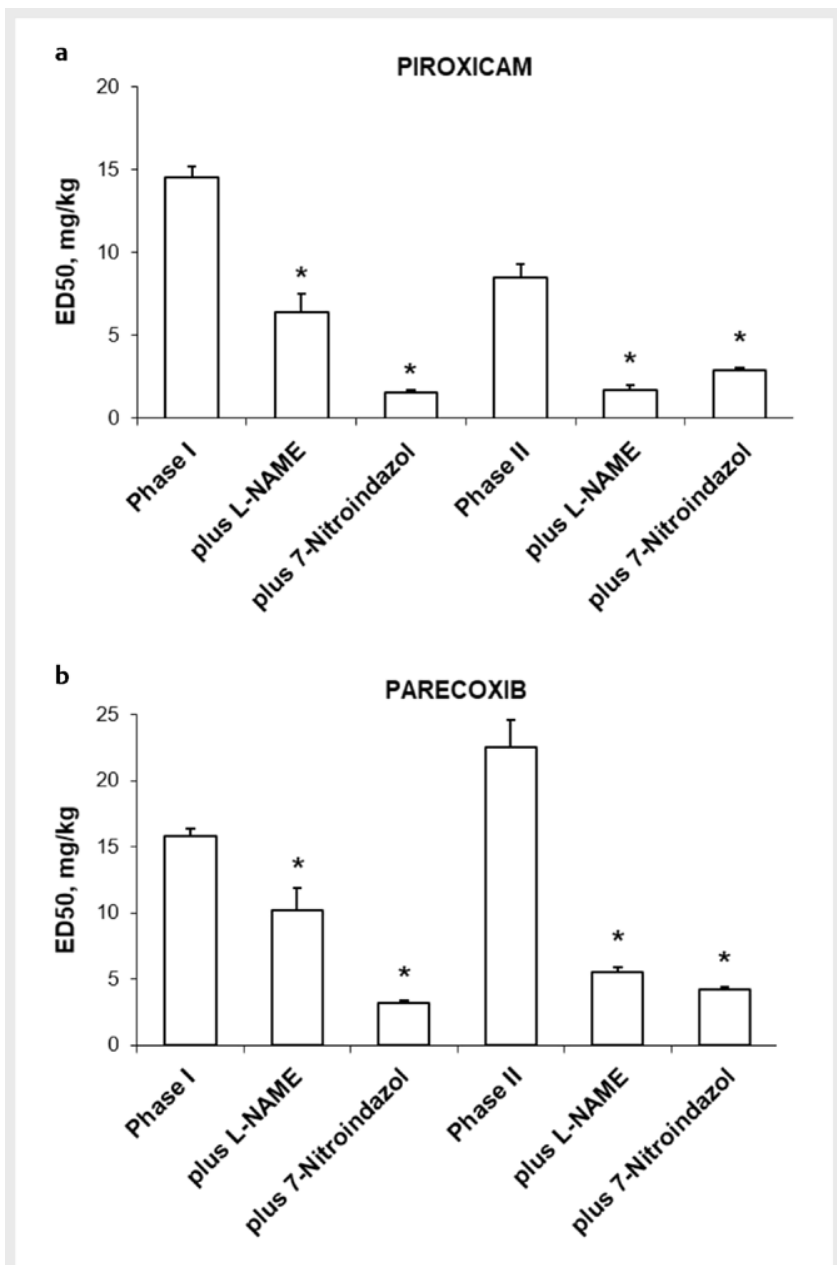

- Fig. $3 E D_{50}$, in $\mathrm{mg} / \mathrm{kg}$, of piroxicam in phase I and in phase ll after pretreatment of L-Name or 7-nitroindazole (3a) and parecoxib in phase I and in phase II after pretreatment of L-Name or 7-nitroindazole (3b). Each point is the mean \pm SEM of 6-8 mice. ${ }^{*} \mathrm{p}<0.05$.

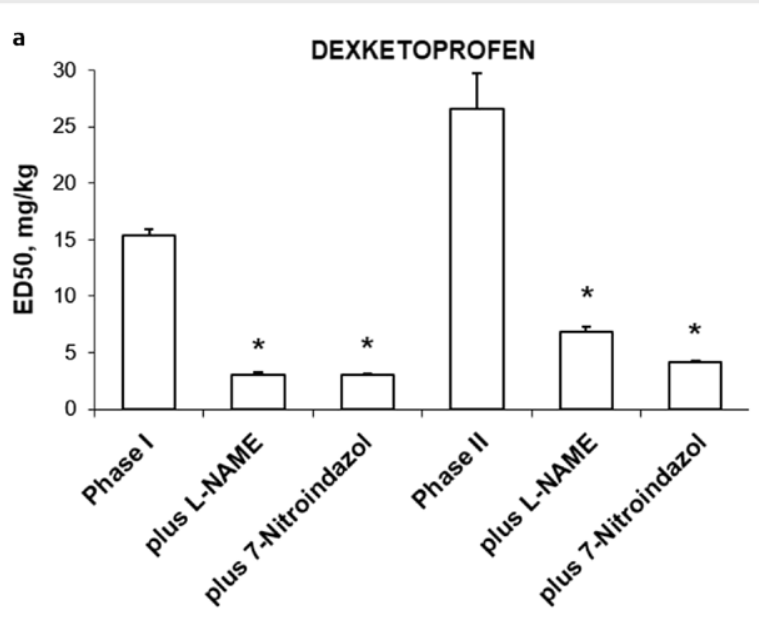

b

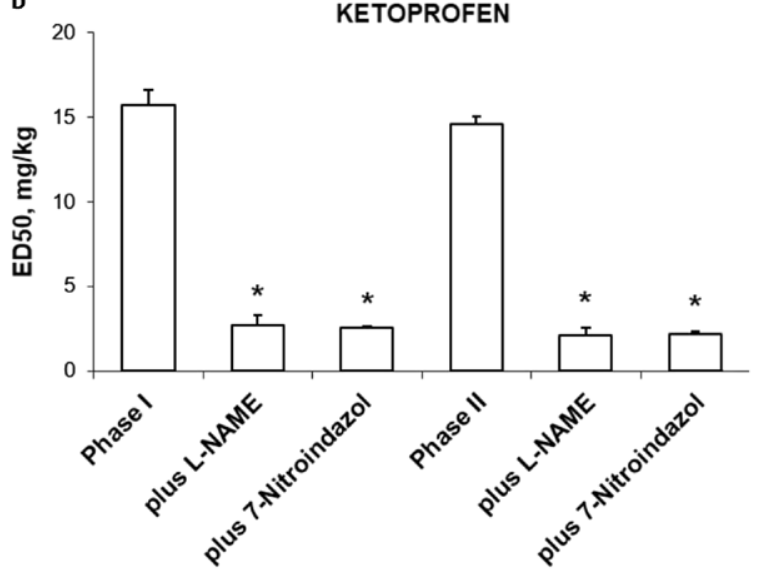

- Fig. $4 \mathrm{ED}_{50}$, in $\mathrm{mg} / \mathrm{kg}$, of piroxicam in phase I and in phase ll after pretreatment of L-Name or 7-nitroindazole (4a) and parecoxib in phase $I$ and in phase II after pretreatment of L-Name or 7-nitroindazole (4b). Each point is the mean \pm SEM of 6-8 mice. ${ }^{*} \mathrm{p}<0.05$. of L-NAME, follows the following course in phase II: ketoprofen, then piroxicam, parecoxib and finally dexketoprofen. In relation to the effect of 7-nitroindazole, the decrease in DE50 is initiated by ketoprofen, followed by dexketoprofen and parecoxib, ending with piroxicam. In summary, the increase in antinociceptive potency, evaluated by a significant decrease in the $\mathrm{ED}_{50}$ of NSAIDs, produced by both L-NAME and 7-nitroindazole, has a higher affinity for COX-1 inhibitors than for COX-2 inhibitors.

The increase in the potency of NSAIDs, reported in this work, by the action of NOS inhibitors, seems to be due to the effect on each of the components. So, first the effectiveness of the non-selective inhibitor NOS, L-NAME and the selective nNOS inhibitor, 7-NI in increase the power of piroxicam, parecoxib, dexketoprofen and ketoprofen indicates that NO activity is involved in both phases of the hind paw formalin test. It is know, that after formalin administration, induces the release of substance $P$ and glutamate and finally the release of NO that provokes central sensitization [19,24].Furthermore, studies with NOS inhibitors and cyclooxygenase inhibitor, suggest that NO stimulates the activity of COX. nNOS and
L-NAME has been involved in the spinal transmission of nociception in animal models of acute and chronic pain [7, 11, 13, 14, 26, 27]. On the other hand, the results obtained in this study, demonstrated that NO was involved in the mechanism of antinociception of piroxicam, parecoxib, dexketoprofen and ketoprofen in both phases of the hind paw formalin test. The mechanism of this antinociceptive action is similar to that previously described for baclofen, morphine, dipyrone, diclofenac, acetylcholine, bremazocine, xylazine and others [21, 22, 28].

In the present study, a significant increase in the potency of some NSAIDs is reported due to NOS inhibitors. However, it is suggested that in addition to the COXs-NO interaction, other mechanisms of action that have been attributed to NSAIDs and that could contribute to the findings described should be taken into account. Among them are: interaction with endocannabinoids, monoaminergic and cholinergic systems [29]. In addition, others such as lactoferrin modulation; inhibition of prostaglandin keto reductase; phospholipase action; negative regulation of L-selectin; TNF- $\alpha$ or IL-1 $\beta$ inhibition [30]. 


\section{Conclusions}

In this study the intraperitoneal administration of piroxicam, parecoxib, dexketoprofen and ketoprofen produced antinociception in both phases of the mice formalin hind paw assay. The pretreatment of the mice with L-NAME or 7-nitroindazol induced a significant increase of the analgesic power of the NSAIDs, with a significative reduction of the ED50. It is suggested that NO may be involved in both phases of the trial, which means that nitric oxide regulates the bioactivity of NSAIDs.

\section{Author Contributions}

All the authors contributed equally in this article.

\section{Funding}

No funding to support the research of this article.

\section{Conflict of Interest}

The authors declare that they have no conflict of interest.

\section{References}

[1] Barrot M. Tests and models of nociception and pain in rodents. Neuroscience 2012; 211: 39-50

[2] Dubuisson D, Dennis SG. The formalin test: A quantitative study of the analgesic effects of morphine, meperidine, and brain stem stimulation in rats and cats. Pain 1977; 4: 161-174

[3] Tjølsen A, Berge OG, Hunskaar S et al. The formalin test: An evaluation of the method. Pain 1992; 51: 5-17

[4] Furst S. Transmitters involved in antinociception in the spinal cord. Brain Res Bull 1999; 48: 129-141

[5] Miclescu A, Gordh T. Nitric oxide and pain: 'Something old, something new' Acta Anaesthesiol Scand 2009; 53: 1107-1120

[6] Alderton WK, Cooper CE, Knowles RG. Nitric oxide synthase: Structure, function and inhibition. Biochem J 2001; 357: 593-615

[7] Sousa AM, Prado WA. The dual effect of a nitric oxide donor in nociception. Brain Res 2001; 897: 9-19

[8] Paul-Clark M], Gilroy DW, Willis D et al. Nitric xide synthase inhibitors have opposite effects on acute inflammation depending on their route of administration. J Immunol 2001; 166: 1169-1177

[9] Moore PK, Oluyomi AO, Babbedge RC et al. L-NG- nitro arginine methyl ester exhibits antinociceptive activity in the mouse. $\mathrm{Br}$ J Pharmacol 1991; 102: 198-202

[10] Moore PK, Wallace P, Gaffen Z et al. Characterization of the novel nitric oxide synthase inhibitor 7-nitroindazole and related indazoles: Antinociceptive and cardiovascular effects. $\mathrm{Br}$ J Pharmacol 1993; 110 : 219-224

[11] Malmberg AB, Yaksh TL. Spinal nitric oxide synthesis inhibition blocks NMDA-induced thermal hyperalgesia and produces antinociception in the formalin test in rats. Pain 1993; 54: 291-300

[12] Duarte ID, Ferreira SH. L-NAME causes antinociception by stimulation of the arginine-NO-cGMP pathway. Mediators Inflamm 2000; 9: 25-30
[13] Doursout MF, Liang Y, Chelly JE. NOS inhibitors exhibit antinociceptive properties in the rat formalin test. Can J Anaesth 2003; 50: 909-916

[14] Sakurada C, Sugiyama A, Nakayama M et al. Antinociceptive effect of spinally injected L-NAME on the acute nociceptive response induced by low concentrations of formalin. Neurochem Int 2001; 38: 417-423

[15] Miranda HF, Puig MM, Dursteler C et al. Dexketoprofen-induced antinociception in animal models of acute pain: Synergy with morphine and paracetamol. Neuropharmacology 2007; 52: 291-296

[16] Moore PK, Wallace P, Gaffen Z et al. Characterization of the novel nitric oxide synthase inhibitor 7-nitro indazole and related indazoles: Antinociceptive and cardiovascular effects.Br. J. Pharmacol 1993; 110 : 219-224

[17] Zhao YQ, Wang HY, Yin JB et al. The analgesic effects of celecoxib on the formalin-induced short- and long-term inflammatory pain. Pain Physician 2017; 20: 575-584

[18] Talarek S, Fidecka S. Role of nitric oxide in benzodiazepines-induced antinociception in mice. Pol J Pharmacol 2002; 54: 27-34

[19] Mehanna MM, Domiati S, Nakkash Chmaisse H et al. Antinociceptive effect of tadalafil in various pain models: Involvement of opioid receptors and nitric oxide cyclic GMP pathway. Toxicol Appl Pharmacol 2018; 352: 170-175

[20] Gupta R, Gupta LK, Bhattacharya SK. Chronic administration of modafinil induces hyperalgesia in mice: Reversal by L-NG-nitro- arginine methyl ester and 7-nitroindazole. Eur J Pharmacol 2014; 736: 95-100

[21] Aguirre-Bañuelos P, Granados-Soto V. Evidence for the participation of the nitric oxide-cyclic GMP pathway in the antinociceptive action of meloxicam in the formalin test. Eur J Pharmacol 2000; 395: 9-13

[22] Ortiz MI, Granados-Soto V, Castañeda-Hernández G. The NO-cGMP-K + channel pathway participates in the antinociceptive effect of diclofenac, but not of indomethacin. Pharmacol Biochem Behav 2003; 76: $187-195$

[23] Ghorbanzadeh B, Kheirandish V, Mansouri MT. Involvement of the L-arginine/Nitric Oxide/Cyclic GMP/KATP Channel Pathway and PPARY Receptors in the Peripheral Antinociceptive Effect of Carbamazepine. Drug Res (Stuttg). 2019; doi: 10.1055/a-0959-5896

[24] Bujalska-Zadrożny M, Wolińska R, Leśniak A et al. Central antinociceptive effect of tapentadol is increased by nitric oxide synthase inhibitors. Behav Pharmacol 2016; 27: 606-614

[25] Rangel RA, Marinho BG, Fernandes PD et al Pharmacological mechanisms involved in the antinociceptive effects of dexmedetomidine in mice. Fundam Clin Pharmacol 2014; 28: 104-113

[26] Dudhgaonkar SP, Kumar D, Naik A et al. Interaction of inducible nitric oxide synthase and cyclooxygenase- 2 inhibitors in formalin-induced nociception in mice. Eur J Pharmacol 2004; 492: 117-122

[27] Dableh LJ, Henry JL. The selective neuronal nitric oxide synthase inhibitor 7-nitroindazole has acute analgesic but not cumulative effects in a rat model of peripheral neuropathy. J Pain Res 2011; 4: 85-90

[28] Romero TR, Resende LC, Duarte ID. The neuronal NO synthase participation in the peripheral antinociception mechanism induced by several analgesic drugs. Nitric Oxide 2011; 25: 431-435

[29] Hamza M, Dionne RA. Mechanisms of Non-Opioid Analgesics Beyond Cyclooxygenase Enzyme Inhibition. Curr Mol Pharmaco 2009; 2: 1-14

[30] Miranda Hugo F., Noriega Viviana, Sierralta Fernando et al. Non-steroidal anti-inflammatory drugs in tonic, phasic and inflammatory mouse models: Drug Research. 2019; doi 10.1055/a-0956-673 